\title{
Food-induced anaphylaxis: our experience
}

\author{
Camilla Di Paolo ${ }^{1 *}$, Massimo Cinquini ${ }^{2}$, Stefano Minetti ${ }^{1}$, Elena Schlanser ${ }^{1}$, Cinzia Tosoni ${ }^{2}$, Fabio Lodi-Rizzini ${ }^{1}$
}

From Food Allergy and Anaphylaxis Meeting 2011

Venice, Italy. 17-19 February 2011

\section{Background}

food-induced anaphylaxis is the most common single cause of anaphylaxis treated in Emergency Department.

\section{Method}

25 outpatients ( 15 females, 10 males; mean age 39 years, range 15-68) who experienced previous anaphylactic reactions, following the exposure to a likely food allergen, were evaluated. The diagnosis of anaphylaxis was performed according to the 2005 criteria. Detailed history and physical examination of patients, skin prick test (SPT) with food commercial extracts and with aeroallergens and panallergens LTP and profilin (Alk), prick-toprick with fresh foods, and serum specific IgE detection (CAP, Phadia) were performed in order to confirm the causative role of the suspected food. Oral food-challenges with positive tested foods were not performed, because of previous severe anaphylaxis. Only in one patient a single-blind placebo-controlled food-challenge (with tomato, positive to SPT but negative to history) was performed, resulting negative.

\section{Result}

briefly, according to Literature, the main involved foods were nuts, crustaceans and mussels, umbelliferae, but also other foods like buckwheat or rabbit meat or acetic acid were sometimes involved.

\section{Conclusion}

our data confirm the importance of performing prick to prick with fresh allergen sources, as they increase CAP positive predicted value and enable the clinician to test unusual allergens. Commercial extracts of the panallergens profilin and LTP were useful tools both for the diagnosis of food allergy and for future dietary management. Although epinephrine is the treatment of choice in anaphylaxis, and most patients fulfilled at least 3

${ }^{1}$ Medicine - University of Brescia, Allergy Unit, Brescia, Italy

Full list of author information is available at the end of the article criteria of anaphylaxis, the drug was administered only in five cases. Fortunately, no patient underwent biphasic reactions, complications, or death.

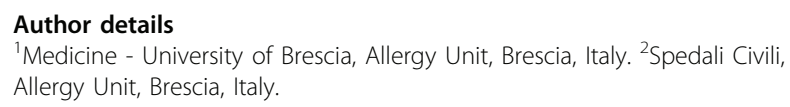

Published: 12 August 2011

doi:10.1186/2045-7022-1-S1-P56

Cite this article as: Di Paolo et al:: Food-induced anaphylaxis: our experience. Clinical and Translational Allergy 2011 1(Suppl 1):P56.

\section{Submit your next manuscript to BioMed Central and take full advantage of: \\ - Convenient online submission \\ - Thorough peer review \\ - No space constraints or color figure charges \\ - Immediate publication on acceptance \\ - Inclusion in PubMed, CAS, Scopus and Google Scholar \\ - Research which is freely available for redistribution

